\title{
Preface: Biology and ecology of the durophagous stingrays
}

\author{
Matthew J. Ajemian • Julie A. Neer
}

Received: 16 June 2013 / Accepted: 18 June 2013 / Published online: 8 July 2014

(C) Springer Science+Business Media Dordrecht 2014

Known for their large-scale migrations, surface schooling behavior and impressive durophagy, the myliobatid and rhinopterid stingrays have long fascinated naturalists and researchers worldwide. However, research on the biology and ecology of these animals has considerably lagged behind other groups of fishes, even within societies dedicated to the study of elasmobranchs
(Fig. 1). This large data gap has undoubtedly impeded the development of management measures for these species despite recently increased exploitation of rays by artisanal fisheries worldwide, and the rising number of kill tournaments targeting stingrays in the USA.

With support from Save Our Seas Foundation and the American Elasmobranch Society, we utilized the venue
Fig. 1 Stacked vertical bar chart of presentations by taxonomic group at the American Elasmobranch Society Annual meeting (1985-2012). While there has been a steady increase in the number of overall talks, they are still dominated by sharks

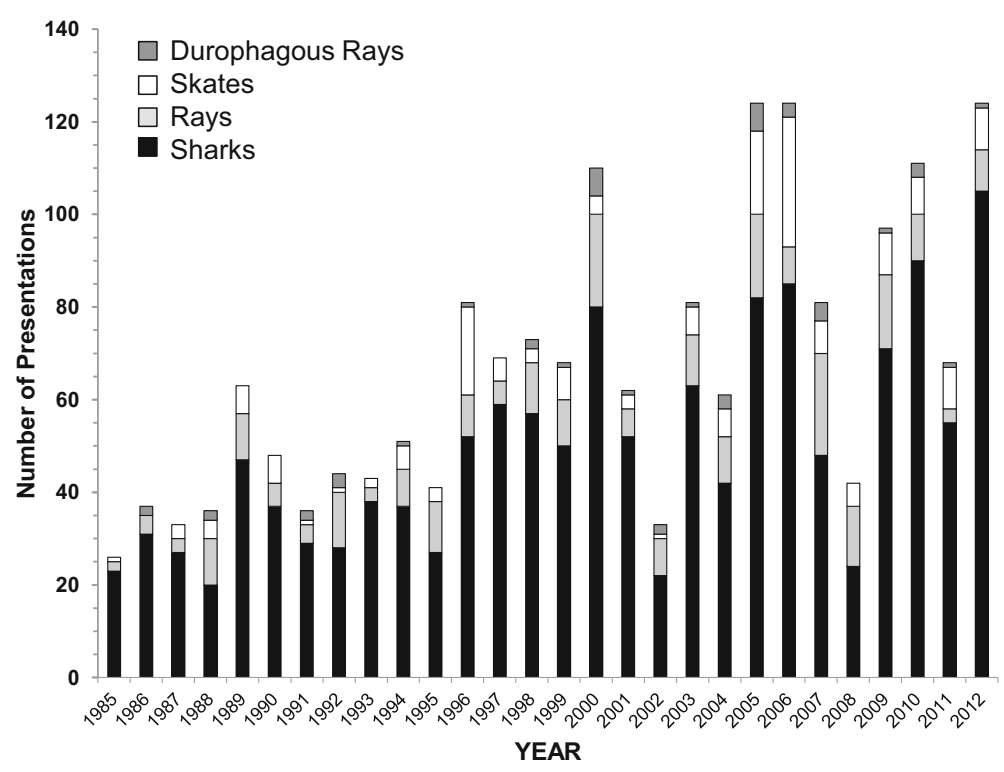

M. J. Ajemian ( $\bowtie)$

Harte Research Institute for Gulf of Mexico Studies,

Texas A \& M University-Corpus Christi,

Corpus Christi, TX, USA

e-mail: Matt.Ajemian@tamucc.edu

J. A. Neer

SEDAR, South Atlantic Fishery Management Council,

North Charleston, SC, USA of the 2013 Joint Meeting of Ichthyology and Herpetology (Albuquerque, New Mexico, USA) to organize a symposium on the biology and ecology of durophagous stingrays. The symposium gathered an international community of scientists (Fig. 2) to consolidate the current state of knowledge on these underrepresented fishes. Included in this special issue is a subset of the 
Fig. 2 Photograph of symposium participants at the American Elasmobranch Society meeting in Albuquerque, New Mexico. Back Row: J. Neer, J.M. Drymon, J. Szczepanski, A. Shaw, M. Kolmann, S. Fordham, G. Poulakis, D. Grubbs, J. Newby. Front Row: C. Bedore, K. St. Clair, L. Bade, J. McDowell, A. Yamaguchi, M. Ajemian. Not pictured: K. Bassos-Hull, S. Powers, J.C. Pérez-Jiménez, R. Fisher. Photo credit: M.D. Potenski

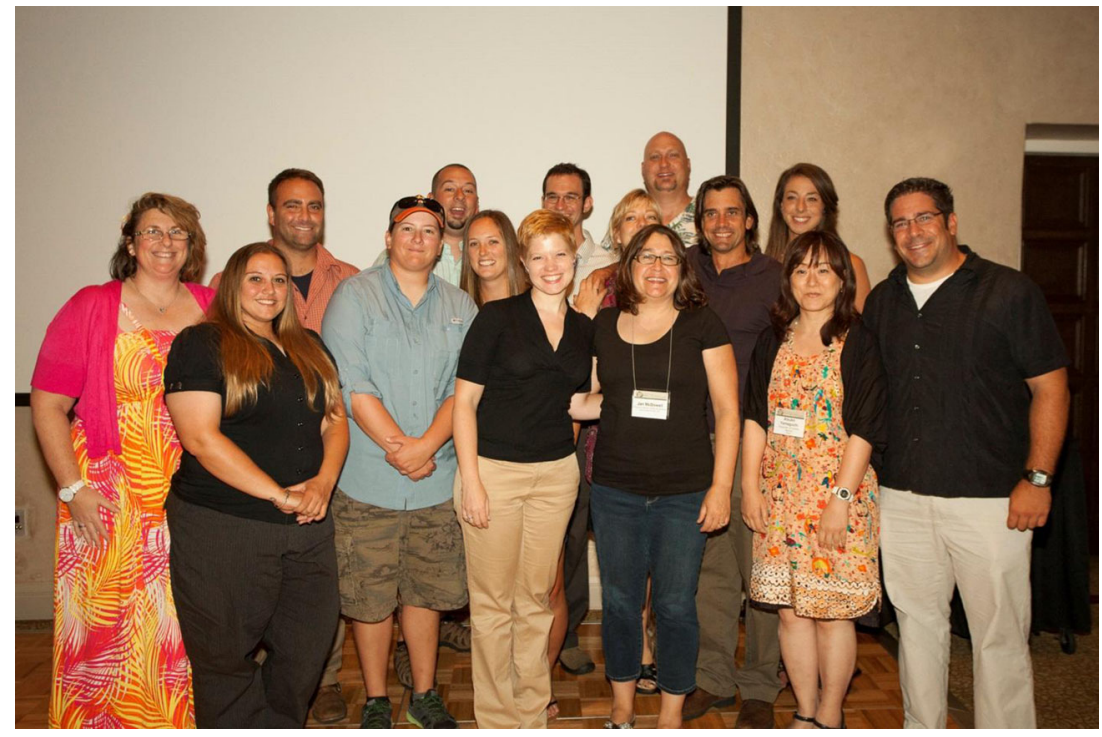

symposium presentations documenting the latest findings on phylogenetic relationships (Aschliman), diet and food habits (Sczcepanski, Bade), reproduction and life history (Poulakis, McDowell, Bassos-Hull), as well as genetic (Newby) and biotelemetry (Ajemian) techniques to investigate spatial ecology and population connectivity of these stingrays. These papers, as well as other presentations not included in the issue, were vital to the symposium discussions concerning the sustainability of a growing fishery for cownose rays (Rhinoptera bonasus) in Chesapeake Bay, USA. It is our hope that this special issue will serve as a rich resource for future management measures involving these potentially ecologically important species, and stimulate further research into durophagous stingray biology and ecology.

We thank all of the participants who attended the symposium and all of the authors who submitted manuscripts for this compilation in Environmental Biology of Fishes. Additionally, the guest editors thank those who served as reviewers during this process. We are most grateful to David L. G. Noakes, the Editor-in-Chief of the journal, and Lynn Bouvier, the managing editor, for their continued support and assistance. Funding for the symposium came from Save Our Seas Foundation and the American Elasmobranch Society. 